\title{
Properties of weld overlays on regenerated wheel hub of a mining vehicle
}

\author{
Andrzej Ambroziak ${ }^{1}$ Artur Lange ${ }^{1, *}$, Piotr Białucki $^{1}$, Michał Kaczmarek ${ }^{1}$ \\ 1 Wrocław University of Science and Technology, Poland \\ Prof. Andrzej Ambroziak, andrzej.ambroziak@pwr.edu.pl \\ Dr. Piotr Białucki, piotr.bialucki@pwr.edu.pl \\ Michał Kaczmarek, 229114@student.pwr.edu.pl \\ * Correspondence: Dr. Artur Lange, artur.lange@pwr.edu.pl
}

\begin{abstract}
The paper presents problems related to the regeneration of wheel hubs for mining machinery vehicles carried out with arc welding using the MAG method. Hubs made of medium-carbon cast steel, type LII500, were weld surfaced with filler metal grade of G4Si. The tests were aimed at determining welding imperfections and metallographic properties of the surfacing welds. The influence of heat treatment on the properties of surfacing was investigated. Hardness distributions in welded hubs after various heat treatment operations were determined. Recommendations for the technology of weld surfacing the wheel hubs were formulated.
\end{abstract}

Keywords: hardfacing; surface modification; pad welding; remanufacturing; coatings

\section{Introduction}

The hardfacing processes are an increasingly used method of restoring operational properties of machine parts [7:9]. Working machines used in the mining industry, and in particular those working directly in the extraction of spoil in mining conditions, are subjected to very difficult conditions that occur during operation. Intensive wear is caused by parts exposed to direct contact with spoil, such as parts of loaders [1,2], walls of haulage trucks boxes [3,4], as well as parts of the transmission system of machines transporting spoil [1,2]. Welding is a commonly used technology for the repair of mining machinery parts $[5,10,12]$. All machine elements are subjected to very heavy loads resulting from the large load capacity of haulage vehicles moving on uneven and heterogeneous ground. One of the most important parts of the suspension system of mining vehicles is the wheel hub. Figure 1 shows an example of a mining machine whose hubs are regenerated. As a result of wear of the surface of the bearings, looseness in the suspension increases and the driving properties of the vehicle deteriorate significantly. Therefore, it is necessary to ensure the proper technical condition of the vehicle enabling its permanent and safe operation. Due to the different

degree of wear of the wheel hub, two solutions are possible, namely replacement for a new part or its regeneration, which is not only a more economical option, but can also improve the properties of the hub. An additional benefit is that repairs of mining machines can also be made on site in an underground workshop.

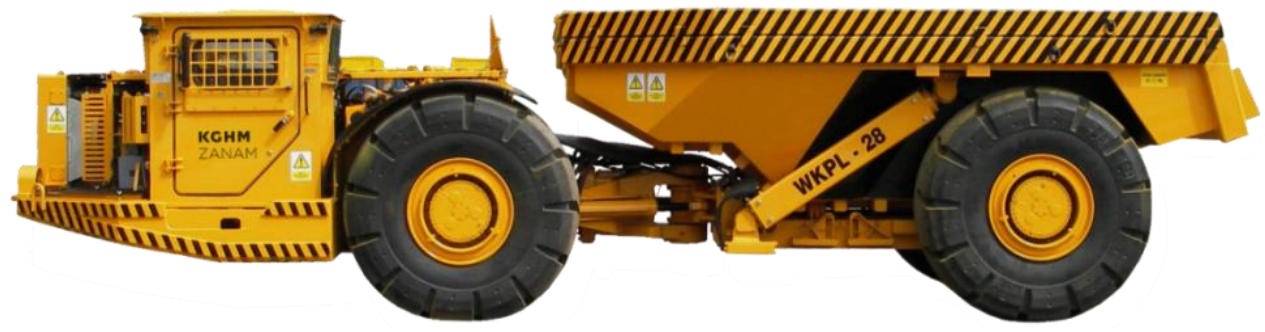

Fig. 1. WKPL-28 haulage truck

\section{Subject of the research}

The subject of the research was a regenerated wheel hub of a haulage truck, which is shown in figure 2. Regeneration consisted of applying a metal layer in the MAG welding process. The hub was made of medium-carbon construction cast steel. The surfacing was made in mine conditions underground. In the welding process, a welding wire, $\varnothing 1,0 \mathrm{~mm}$, grade G4S1 was used. A gas mixture of Ferroline C18, MESSER, 
which is a mixture of $18 \%$ carbon dioxide in argon, was used as the shielding gas. The padding welds were laid in one layer.

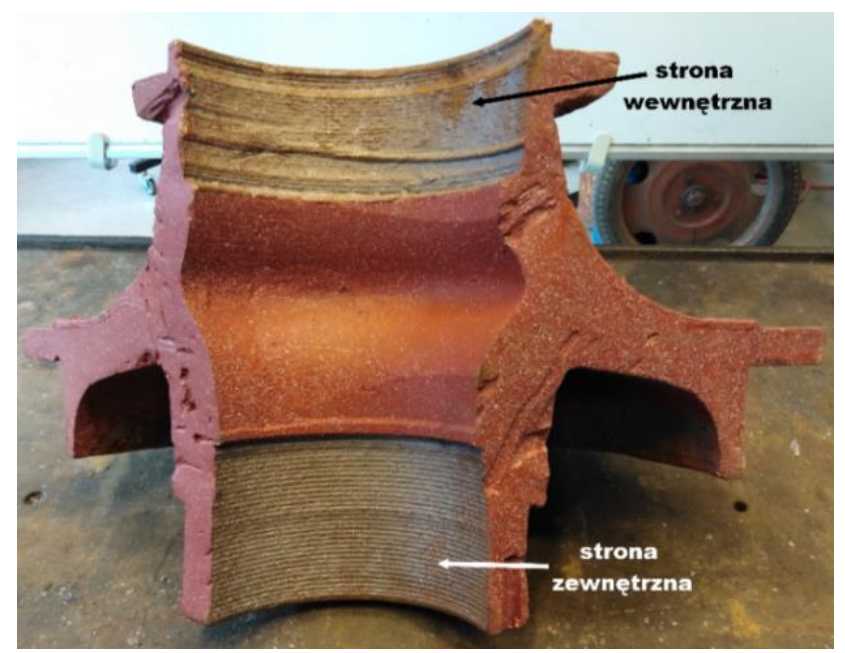

Fig. 2. A fragment of the wheel hub after weld surfacing the seats under the bearing before machining

In the process, the STEL MAX 503 IP 54-ATX device was used as the power source, with the addition of iD Weld 2501 (Fig. 3).

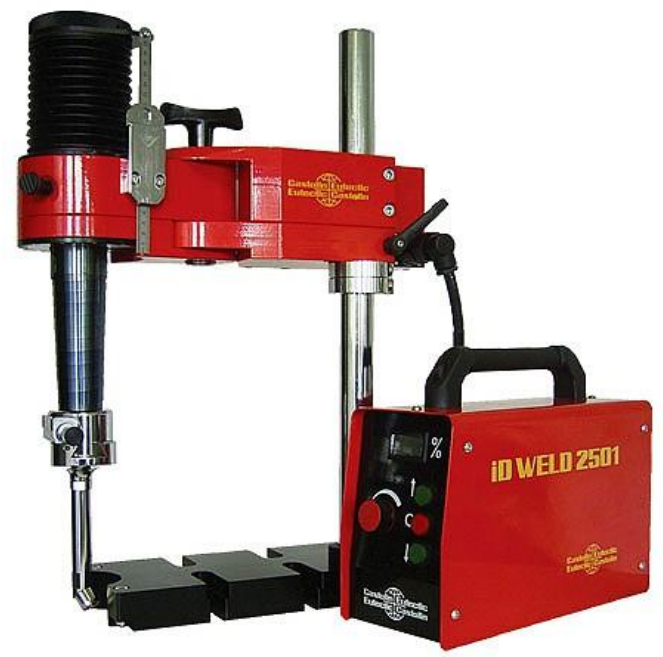

Fig. 3. Device for orbital welding with the GMA method of internal and external surfaces iD Weld 2501

As part of the renovation of the hub, the following works were carried out:

1. Washing the hub;

2. Disassembly of bearing rings and brake disc;

3. Sandblasting of the hub;

4. Damage verification;

5. Preparation of welding sockets;

6. Hardfacing the sockets under the bearing with an automatic padding machine;

7. Effusing of the sockets;

8. Protection of the surface before painting;

9. Painting the hub;

10. Mounting of bearing rings and assembly of a new brake disc.

\section{Chemical composition analysis}

The analysis of the chemical composition (Table I) of the hub material and the padding weld layer was carried out using the spectral method using a LECO GDS-750-QDP glow discharge spectrometer. After the analysis of the chemical composition, it was found that the material of the hub corresponds to the mediumcarbon cast steel, type LII500, according to the requirements of PN-H-830152: 1985, and the padding weld material corresponds to a partial mixing of the cast steel with the G4S1 grade alloy wire. 
Table I. Analysis of the chemical composition of the wheel of a haulage truck

\begin{tabular}{ccccccccccc}
\hline & $\mathbf{C}$ & $\mathbf{S i}$ & $\mathbf{M n}$ & $\mathbf{P}$ & $\mathbf{S}$ & $\mathbf{M o}$ & $\mathbf{C r}$ & $\mathbf{N i}$ & $\mathbf{C u}$ & $\mathbf{A l}$ \\
\hline Padding weld & 0.16 & 0.61 & 1.10 & 0.121 & 0.040 & 0.02 & 0.06 & 0.03 & 0.10 & 0.01 \\
Hub & 0.32 & 0.32 & 0.61 & 0.223 & 0.032 & 0.04 & 0.12 & 0.04 & 0.09 & 0.04 \\
PN-H-83152 & $0.15 \div 0.30$ & $0.20 \div 0.50$ & $0.40 \div 0.90$ & 0.06 & 0.04 & 0.10 & 0.40 & 0.35 & 0.30 & - \\
\hline
\end{tabular}

Noteworthy is the high content of phosphorus in the cast steel, which may be the reason for high sensitivity to cracks in the padding weld and in the mixing layer. However, the presence of such cracks in the padding weld areas was not found, but hot cracks were noted in the material of the hub, as shown in figure 14 .

\section{Macroscopic examinations}

Macroscopic examinations were carried out according to PN-EN 1321:2000 using the ZX7 OLYMPUS stereoscopic microscope on the cross-sections of the hardfaced hub, shown in figure 4.
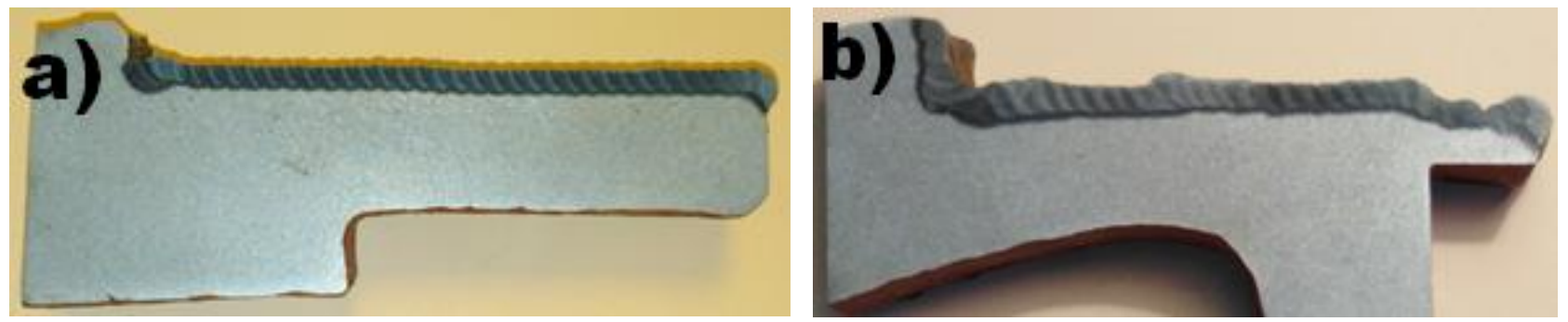

Fig. 4. View of the cross-section of the wheel hub after weld surfacing: a) the outer side, b) the inner side. Etched with $10 \%$ nital

Due to the uneven internal wear of the hub, the padding welds have a completely different shape. The hub bore from the inside is subject to greater wear and requires a thicker padding weld to be laid than the outside. Sometimes it forces the creation of an additional layer in order to obtain the proper diameter of the hub before machining. Macroscopic tests confirmed greater unevenness of the layers and showed the need for proper preparation of the hub bores before the regenerative deposition process. Regeneration layer, created on the outside, is characterized by high uniformity of the surface and evenness of the amount of heat introduced. The internal side requires additional regeneration processes increasing costs and extending the repair time, in addition there is a higher probability of cracks due to the inhomogeneous amount of heat introduced.

Macroscopic examinations additionally revealed some shortcomings in the hardfacing technology, i.e. blister at the fusion border (Fig. 5), lack of fusion and emptiness in the corner (Fig. 14).
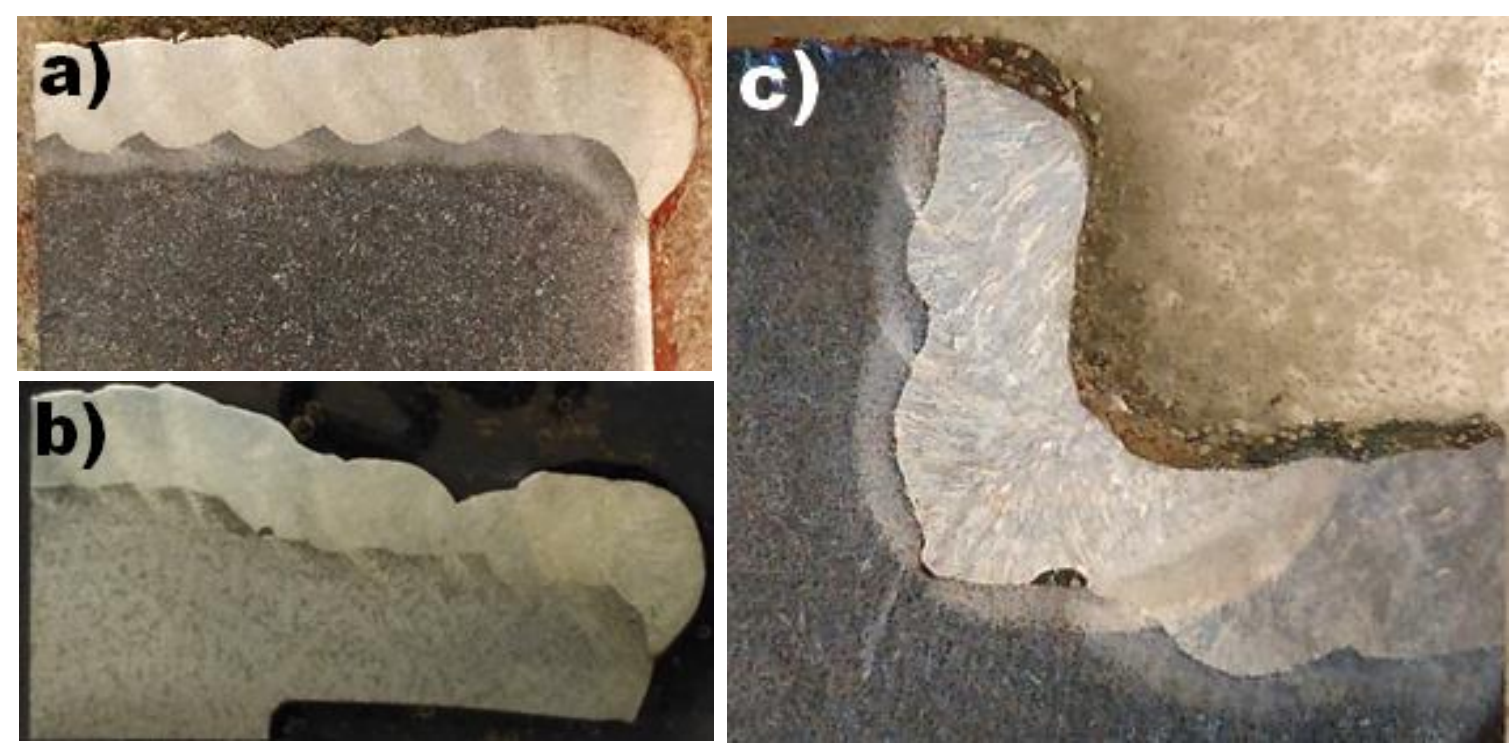
Fig. 5. View of the cross-section of the wheel hub weld surfacing in selected places of padding welds: a) outer side - end edge, b) inner side - end edge; c) inner side - internal corner. Etched with 5\% nital.

\section{Hardness}

Hardness was measured using the Vickers method according to PN-EN ISO 9015-2:2011 at $10 \mathrm{~N}$ load on the SINOWON HVS-1000 hardness tester. Samples for hardness measurements were taken from the locations shown in Figure 6. The distribution of hardness on the cross-section of the hardfaced sample was made on raw samples (samples a, c and g), on stress relief annealed samples (samples e and f) and on samples after normalizing annealing (samples b, d). The annealing treatment of samples was carried out in accordance with the recommendations of PN-H-83152 for cast steel LII500, stress relief annealing temperature $600^{\circ} \mathrm{C}$, and normalizing annealing $920^{\circ} \mathrm{C}$. Distributions of hardness in the tested samples are presented in Figures $7 \div 9$.
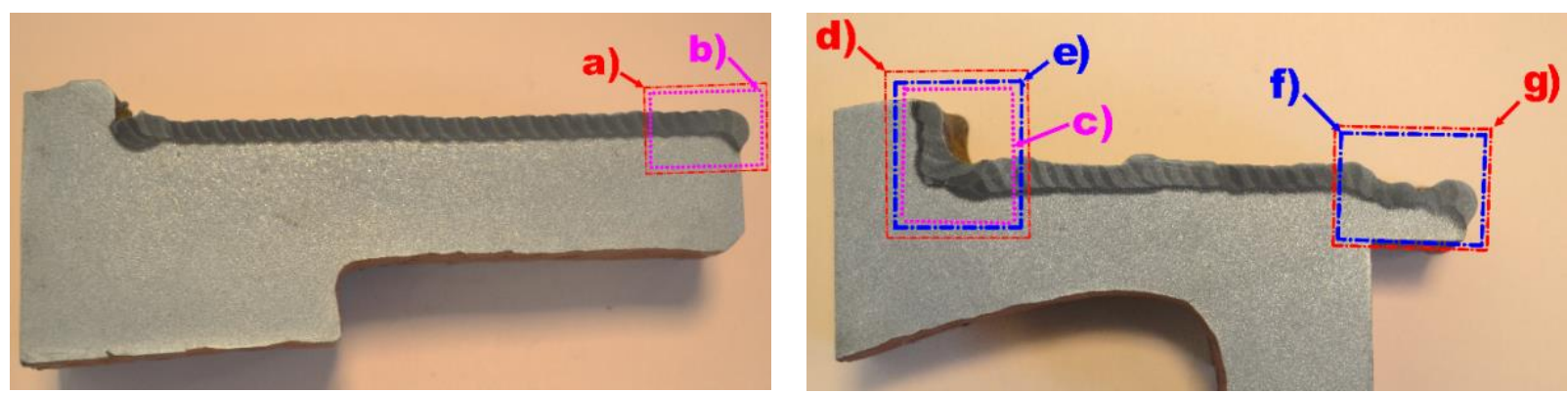

Fig. 6. Place and type of sample for metallographic section and microhardness measurements: $b, d$, $g$ - after weld surfacing, a, c - after normalizing annealing, e, f - after stress relief annealing

Hardness measurements showed that samples in the raw state after hardfacing were characterized by a sharp increase in hardness of up to $536 \mathrm{HV} 1$ in the HAZ under the last bead (series 1 in Fig. 7). On the other hand, underneath the earlier beads there was a decrease in hardness caused by the thermal effect of the next bead. In the case of padding weld, the hardness was about 220 to $255 \mathrm{HV} 1$, while the hardness of the material of the hub was between 150 and 175 HV1. Due to the fact that the welding of the hub was carried out without preheating, additional tests were carried out to determine the impact on the material structure and its hardness of possible post-weld heat treatment, including stress relief annealing and normalizing annealing.
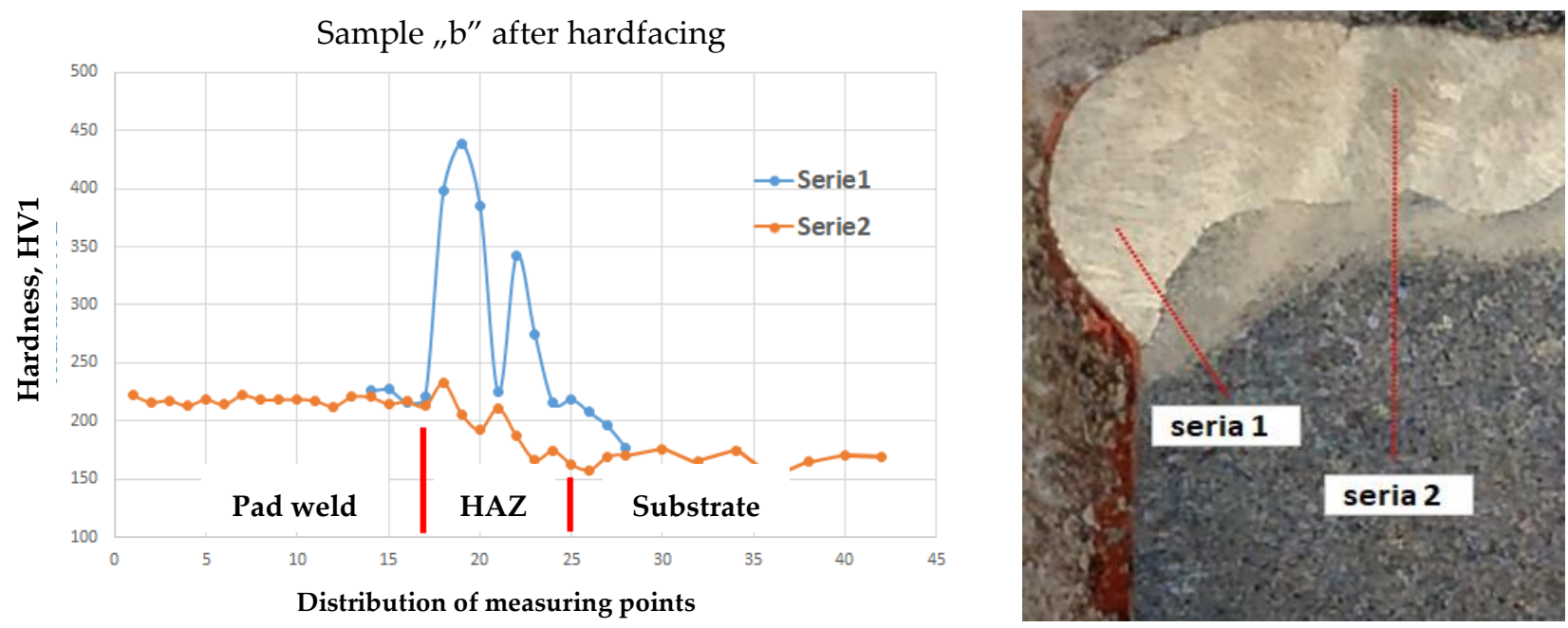

Fig. 7. Distribution of hardness on the cross section of the sample of the hub in the state after weld surfacing. Sample "b" from the outside of the hub

Examination of the samples after stress relief annealing at $600{ }^{\circ} \mathrm{C}$ showed a significant decrease in the hardness of the HAZ under the last bead from approx. 536 HV1 to 293 HV1 (Fig. 9). There was a slight decrease in the hardness of the padding weld and the native material of the hub by an average of about 20 HV1. 
However, normalizing annealing at $920{ }^{\circ} \mathrm{C}$ resulted in complete softening of the material and alignment of hardness in the entire area of padding weld-HAZ-hub (Fig. 8). Hardness varies from $155 \mathrm{HV} 1$ to $186 \mathrm{HV} 1$.
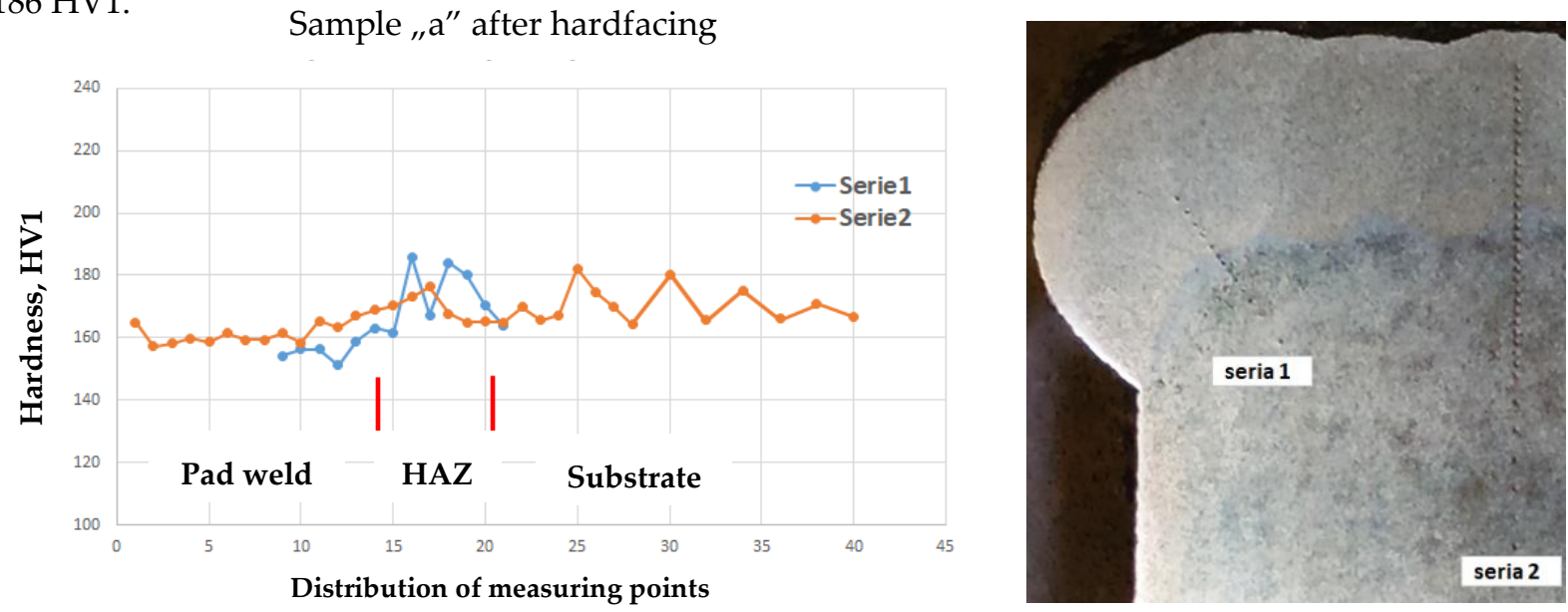

Fig. 8. Distribution of hardness on the cross-section of the sample of the hub in the normalized annealed condition after weld surfacing. Sample "a" from the outside of the hub
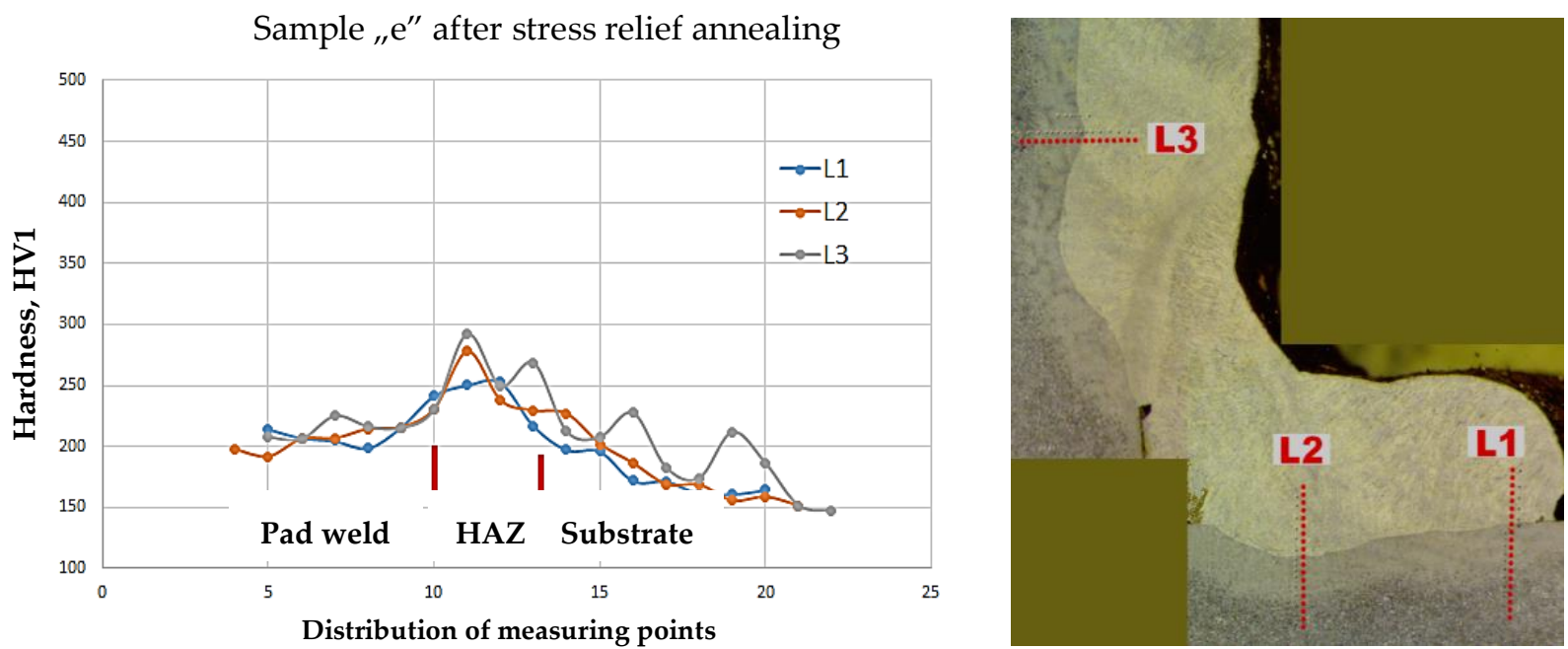

Fig. 9. Distribution of hardness at the cross-section of the sample of the hub in the stress relief annealed condition after surfacing. Sample "e" from the inside of the hub

\section{Microscopic examinations}

Microscopic observations were made according to PN-EN 1321:2000 on metallographic samples a $\div \mathrm{g}$ (Fig. 6) using the Zeiss NEOPHOT 32 light microscope.

Figure 10 shows the padding weld microstructure in the raw state after hardfacing - sample "b". There is a dendritic ferritic structure with a direction of grain in accordance with the direction of heat dissipation in the padding weld (Fig. 10a), there is a martensitic structure in the HAZ (Fig. 10b), whereas in the material of the hub (Fig. 10c) there is a ferrite-perlitic structure with the participation of ferrite in Widmannstätten system. Inside the material of the native hub, the occurrence of local hot cracks can be seen (Fig. 14), which, however, do not reach the surface of the material and do not combine with the padding weld.

Figure 11 shows the microstructure of the hardfaced hub after stress relief annealing. No major changes were observed in the structure of individual hub material zones. However, the hardness distribution (Fig. 9) shows that stress relaxation caused by hardfacing occurred and the hardness decreased to below $300 \mathrm{HV} 1$ level in the HAZ zone.

Hardfacing of the hub in the underground workshop in the mine is carried out without preheating, although the carbon equivalent of $\mathrm{Ce}=0.454 \%$ indicates conditional weldability requiring possible preheating before hardfacing. The pre-heating temperature calculated with the Seferian formula is $164{ }^{\circ} \mathrm{C}$. However, the non-use of pre-heating results from the difficulty of performing such a procedure in underground conditions in the mine, and in addition thermal radiation of the heated hub would hinder the positioning of the welding device on it. 
Due to the fact that machining after the hardfacing process releases stresses, which may result in deformations or cracks, it would be advisable to carry out stress relief annealing. As a result of such annealing, the shape and dimensions of the hub will stabilize, and removal of the surplus of the padding weld's layer by cutting will not cause deformation of the hub bore.
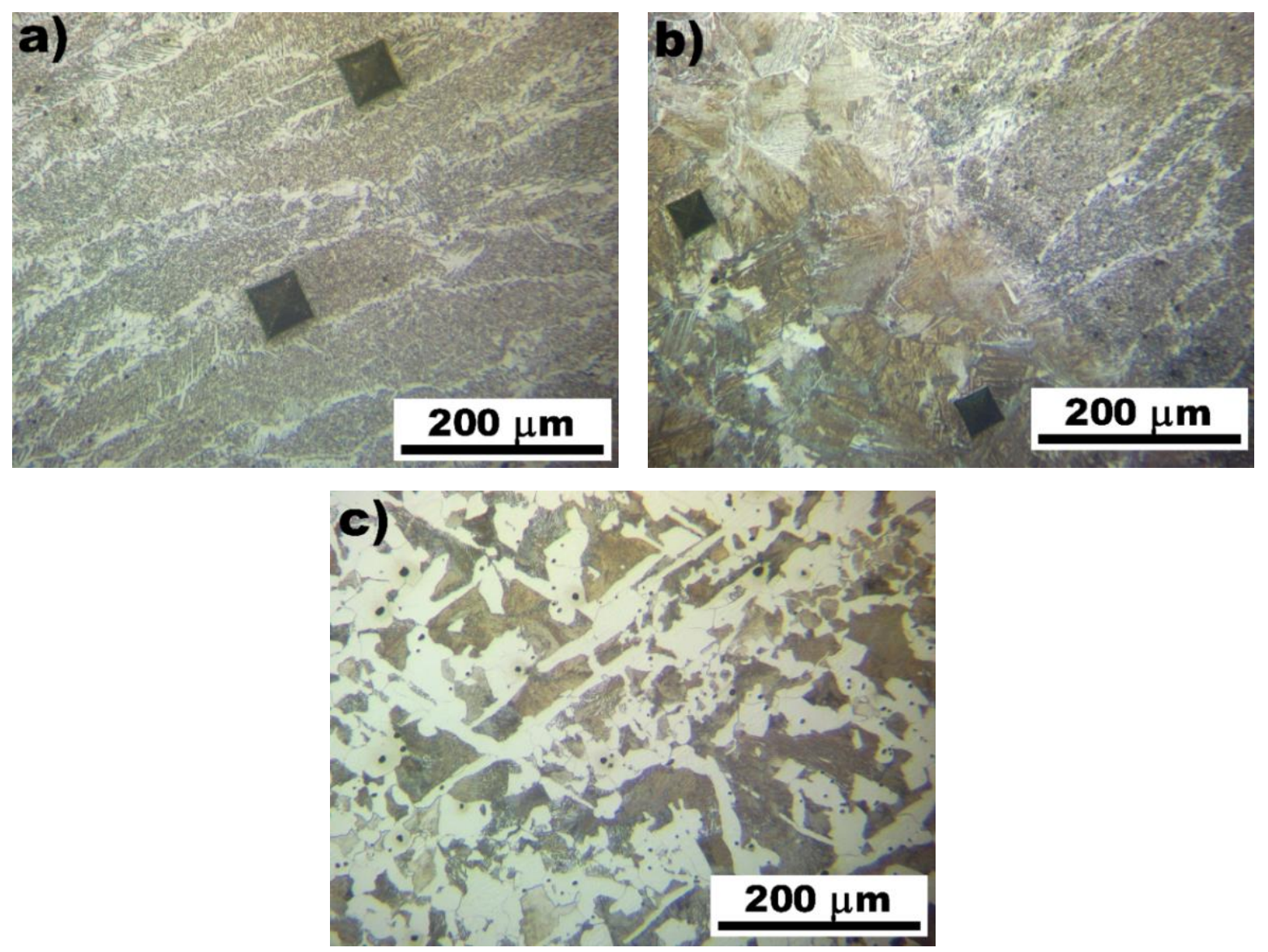

Fig. 10. Pad weld: a) last stitch, b) HAZ + last stitch, c) base material of hub Mag. x200. Etched with $5 \%$ nital
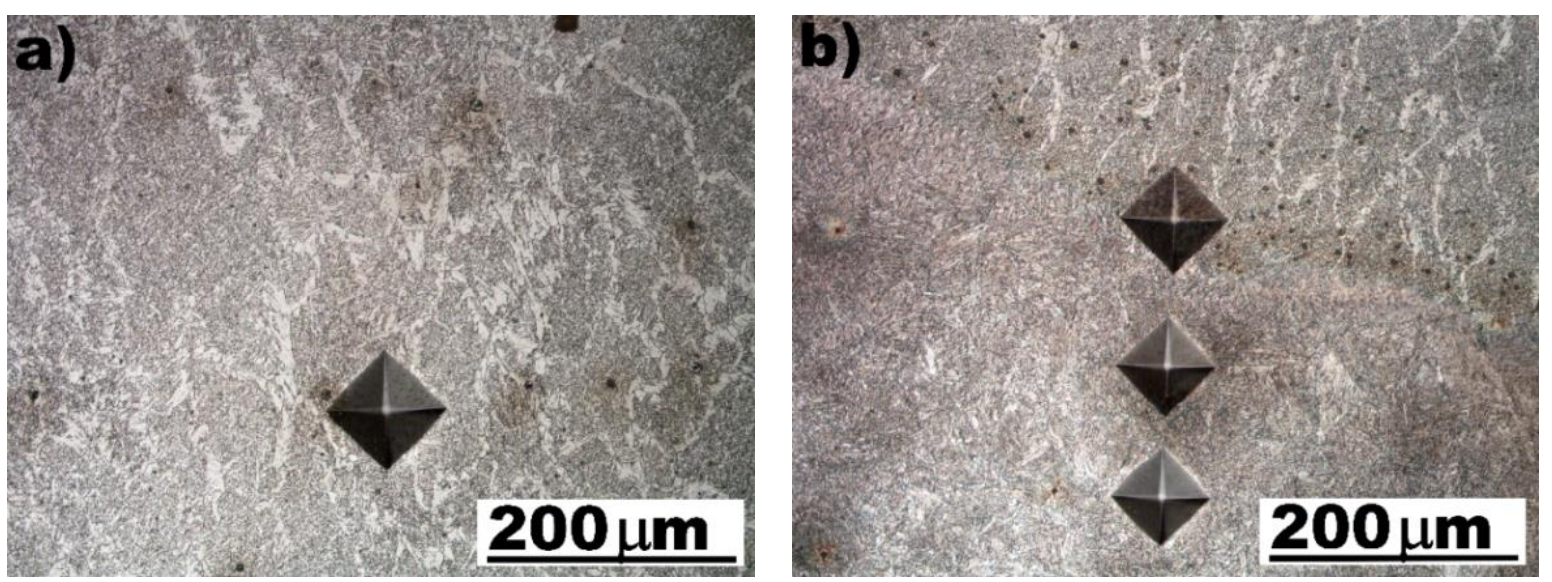


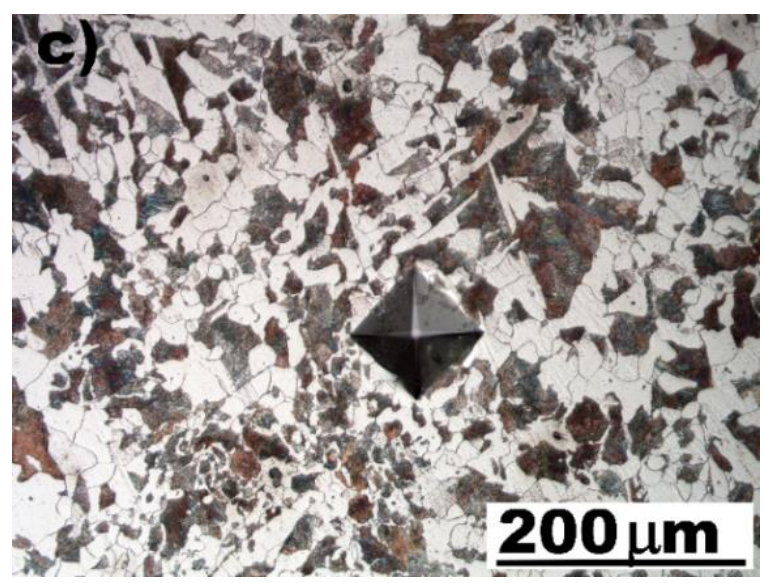

Fig. 11. Weld overlay after stress relief annealing: a) last stitch, b) SWC + last stitch, c) base material of hub. Mag. x200. Etched with $5 \%$ nital

From the microscopic observation of the native material of the hub in the raw state, it follows that the casting was not subjected to heat treatment by normalization, and Widmannstätten's structure size indicates that it was also not stress relief annealed. In the case of steel castings, not only normalizing annealing is used, but also thermal improvement aimed at improving mechanical properties [6]. For testing purposes, the comparison of structures and properties of the hub material, depending on the heat treatment, stress relief and normalization annealing of welded samples was performed. The appearance of the sample structures after normalization is shown in Figure 12. The fragmentation of grains after heat treatment can be seen.
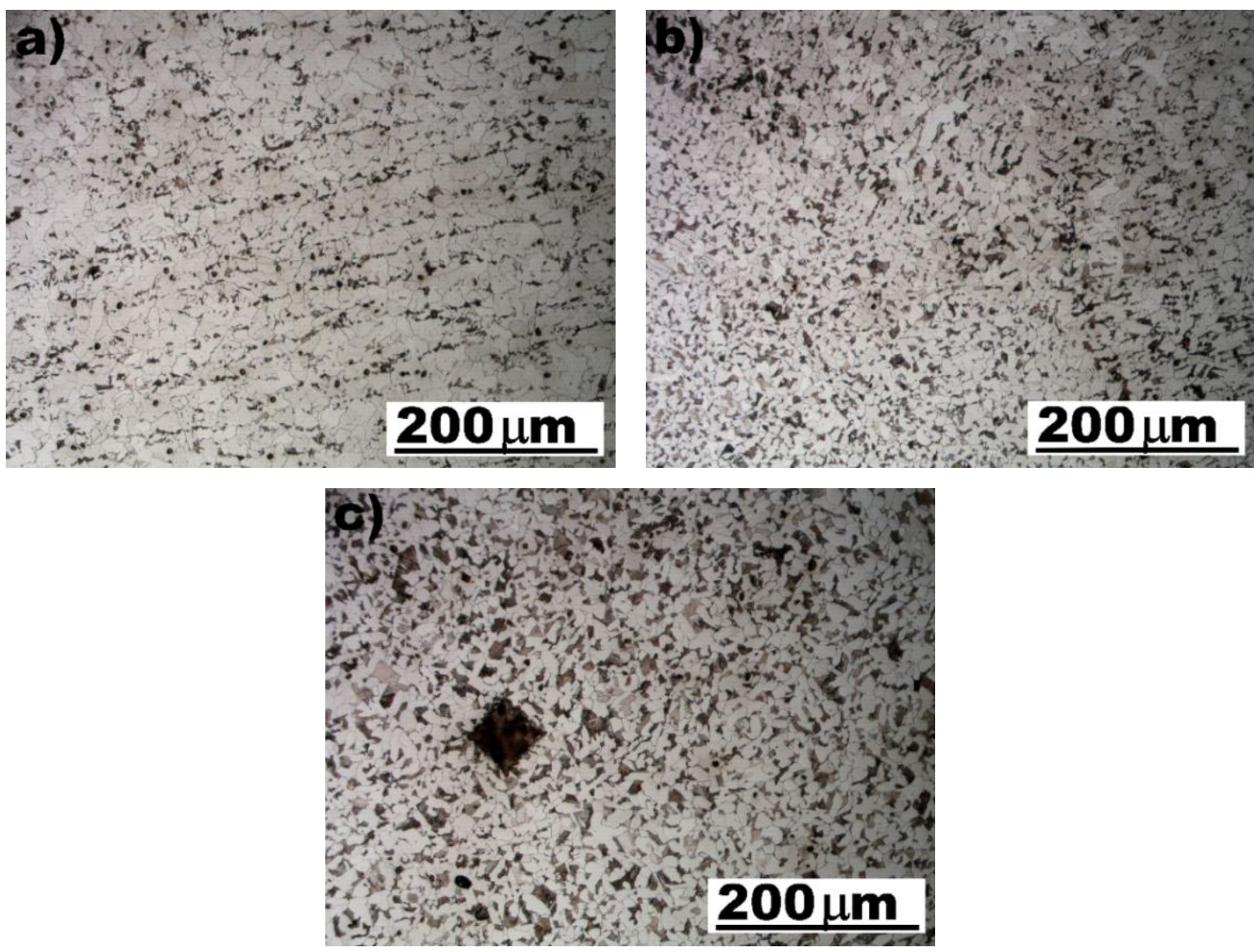

Fig. 12. Weld overlay after normalizing annealing: a) last stitch, b) SWC + last stitch, c) base material of hub. Mag. x200. Etched with $5 \%$ nital

Despite the lack of preheating of the hub before hardfacing, no cracking in the padding weld or in the HAZ was found. However, the lack of such heating was the reason for welding incompatibilities when 
laying the first bead on the cold hub (cracking, lack of fusion, blisters) (Fig. 13). The avoidance of such incompatibilities is possible by increasing the linear energy of the hardfacing in the first weld bead.

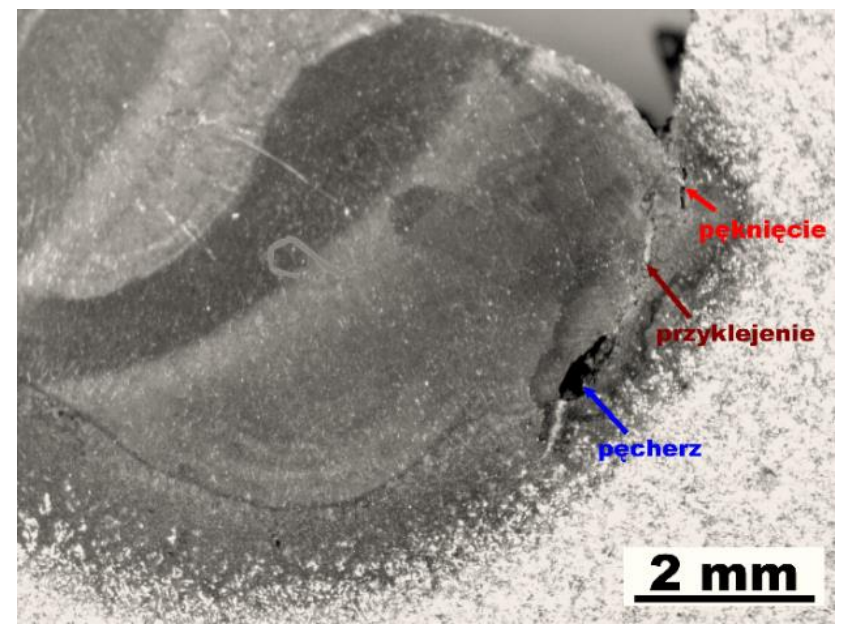

Fig. 13. Weld overlay as welded in the first stitch. Mag. x33. Etched with 5\% nital

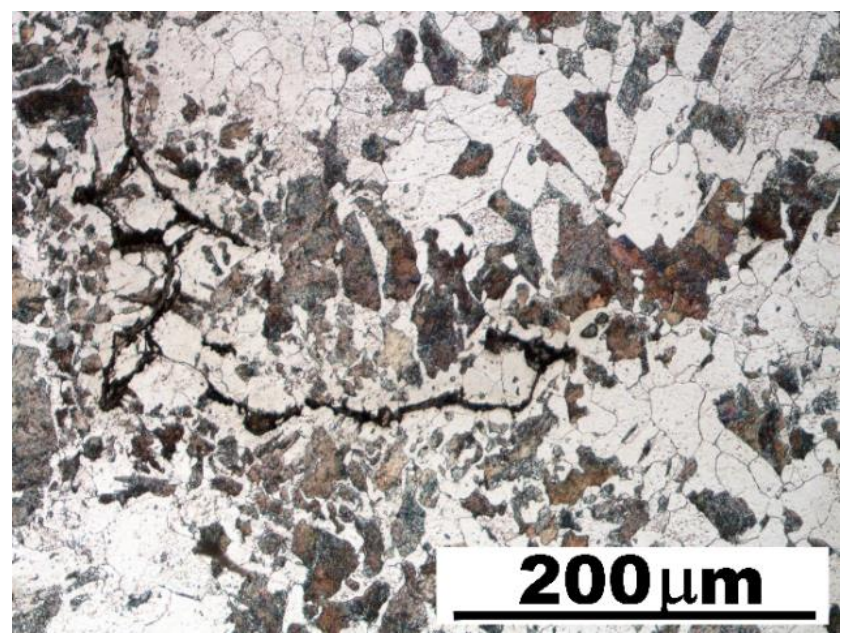

Fig. 14. The base material of the hub in the raw state. View of a hot crack. Mag. x200. Etched with $5 \%$ nital

\section{Summary}

Mining machine wheel hubs are made of medium-carbon cast steel, type LII500. The dependence of mechanical properties of the cast steel on the applied heat treatment after casting has a big impact on their structure, mechanical properties, and especially on weldability. The carbon equivalent of $0.454 \%$ resulting from the chemical composition of the tested cast indicates conditional weldability. In this case, the preferred material structure in terms of welding is the fine-grained structure after normalization or at least the casting should be subjected to stress relief annealing.

Metallographic examinations have shown that the native material of the hub does not indicate that the casting has been subjected to any of the aforementioned heat treatments. Comparative studies of steel structures after various types of heat treatment showed that there is a coarse-grained ferritic-pearlitic structure with ferrite in the Widmannstätten system in the hub material. However, after the normalizing heat treatment, there was a clear change in the structure to the fine-grained ferrite-pearlite structure. The stress relief annealing did not cause a visible change in the structure of the hub cast, but there was a marked change in hardness.

Noteworthy is the unfavourable phenomenon of the presence of hot cracks (Fig. 14) in the native material of the raw casting, caused by the high content of phosphorus in the material (Table I).

The performed tests allowed to detect significant, albeit few, incompatibilities such as blisters, lack of fusion, cracks, lack of penetration and other discontinuities in the structure of the welded hub element. The lack of pre-heating was the reason for welding incompatibilities when laying the first stitch on a cold hub (cracking, lack of fusion, blisters, Fig. 13). The avoidance of such incompatibilities is possible by increasing the linear energy of the welding in the first weld bead. 
The occurrence of some non-conformities, such as lack of fusion and cracks is unacceptable and involves disqualification of the element and the need to re-execute selected parts of the padding weld, which significantly extends the repair time and drastically increases the cost of its implementation.

The research results indicate that in order to reduce the occurrence of nonconformities, in the future, the preheating of the hub in the range of $150 \div 180^{\circ} \mathrm{C}$ should be included in the hardfacing process.

In spite of the abovementioned irregularities in the structure of the hub, the tests have shown that it is possible to fully regenerate the hub bores of mining vehicles directly at the bottom of the mine. The limited weldability of the native material of hub, however, allows hardfacing to be carried out also without preheating, but it requires significant changes in the hardfacing technology, including a very scrupulous technological rigor, which becomes very problematic in mine conditions.

Undoubtedly, the most expedient would be to use at least preheating before the hardfacing process, and an even better would be an additional stress relief annealing of the hub after the hardfacing process. Although it generates higher production costs initially, it avoids deformation of the bore during machining caused by a change in the stiffness of the local cross-section of the hub and making the bore in the required tolerance for the bearing.

\section{References}

1. Rusiński E.; Lewandowski T.; Białucki P.; Kozerski S.; Malcher K.; Słomski W. Review of technologies of repairs and overhauls of mining machines in the aspect of minimizing underground spa-fighting work. Raporty Inst. Konstr. Ekspl. Masz. PWroc. 2001 Ser. SPR nr 53, 93 s. : rys., tab., bibliogr. 4 poz. Rodzaj pracy: raporty serii SPR

2. Rusiński E.; Lewandowski T.; Białucki P.; Kozerski S.; Malcher K.; Słomski W. Review of technologies for repairs and overhauls of mining machines in the aspect of minimizing underground spa work: Stage II. Raporty Inst. Konstr. Ekspl. Masz. PWroc. 2002 Ser. SPR nr 31, 148 s. : rys. Rodzaj pracy: raporty serii SPR

3. Szczepaniuk P. Welding technology of selected mining car subassemblies. M. Sc. thesis PWr, 2005, Promotor dr inż. Piotr Białucki.

4. Dobrzański A. Developing technology for repairing the loader work system. M. Sc. thesis PWr, 2006, Promotor dr inż. Piotr Białucki

5. Białucki P. Rozdz. pt. Repair surfacing of surface elements in the book Maintenance strategy in the movement of opencast mining machinery and equipment with a high degree of technical degradation. Red. Dionizy Dudek. Wrocław: Publishing House of Wrocław University of Science and Technology

6. Żuk M., Dojka R. Repair welding of cast steel G20Mn5. Welding Technology Review, 2018, vol. 90(5), 112-116. [CrossRef]

7. Chmielewski T., Golański D. Znaczenie spawalnictwa w procesie remanufacturingu. Welding Technology Review 2011, vol. 83(6), 29-32.

8. Kuzniecow V.D. Problemy regeneracyjnego napawania. Welding Technology Review, 2011, vol. 83(10), 4-7.

9. Kolasa A.; Sarnowski T.; Cegielski P. Zautomatyzowana regeneracja metodami spawalniczymi zużytych powierzchni części maszyn. Welding Technology Review, 2015, vol. 86(1), 50-57.

10. Selection Guide to Lincoln Hardfacing Materials and Procedures; Publication C7.710. Issue Date 06/14. @ Lincoln Global Inc.

11. Lazić V.; Sedmak A.; Nikolić R.R.; Mutavdžić M.; Aleksandrović S.; Krstić B.; Milosavljević D. Selection of the most appropriate welding technology for hardfacing of bucket teeth. Materials and Technology, 2015, vol. 49(1), 165-172. [Hyperlink]

12. Chippendale D. Cost Reduction to the Mining Industry through the use of Hardfacing Ground Engaging Tools. http://www.arm.com.au/image/data/25-Brochures\%20and\%20Cost\%20analysis\%20thesis/thesis.pdf

(C) 2019 by the authors. Submitted for possible open access publication under the terms and conditions of the Creative Commons Attribution (CC BY) license (http://creativecommons.org/licenses/by/4.0/). 